\title{
Erratum to: The Mechanisms and Meaning of the Mismatch Negativity
}

\author{
Yonatan I. Fishman
}

Published online: 27 December 2013

(C) Springer Science+Business Media New York 2013

\section{Erratum to: Brain Topogr}

\section{DOI 10.1007/s10548-013-0337-3}

The purpose of this erratum is to supplement the following statement in the original review article:

"To the best of the author's knowledge, there is presently no evidence for responses to stimulus omissions in A1 [primary auditory cortex] of animal models, including awake monkeys."

with the following:

However, event-related potentials elicited by stimulus omissions have been recorded from the scalp of rhesus monkeys (Honing et al. 2012). The intracranial sources of these omission responses and the brain networks involved in their generation have yet to be determined.

The reference to Honing et al. (2012) was missing in the original publication of the article.

\section{Reference}

Honing H, Merchant H, Háden GP, Prado L, Bartolo R (2012) Rhesus monkeys (Macaca mulatta) detect rhythmic groups in music, but not the beat. PLoS One 7(12):e51369
The online version of the original article can be found under doi: 10.1007/s10548-013-0337-3.

Y. I. Fishman ( $₫)$

Departments of Neurology and Neuroscience, Albert Einstein

College of Medicine, Kennedy Center, Room 322/915D,

1410 Pelham Parkway, Bronx, NY 10461, USA

e-mail: yonatan.fishman@einstein.yu.edu 